\title{
A roteirização turística dos destinos sob o olhar do mapeamento participativo: contribuições para a busca de um
} turismo inclusivo*

Tourist Routing of Destinations under the View of Participatory Mapping: contributions to the search for inclusive tourism

Diego Uliano Rocha ${ }^{1}$

\begin{abstract}
* Recebido em: 13.04.2020. Aprovado
\end{abstract}
Resumo: o presente ensaio tem como objetivo pensar a rentabilidade analítica do conceito "mapeamento participativo" na avaliação da participação social no processo brasileiro de roteirização turística. A necessidade deste trabalho surge no contexto contemporâneo de garantir maior protagonismo da população receptora no desenvolvimento da atividade turística em seus espaços de vida. Para isso é feita uma revisão bibliográfica sobre as discussões de roteirização turística no Brasil junto a abordagens teóricas sobre as possibilidades de roteiros turísticos na ótica do mapeamento participativo. O item em destaque nestas análises é o grau de inclusão da comunidade. Assim, será possível verificar se o conceito em voga colabora ou não, de forma significativa, para pensar e fazer roteirizações turísticas mais inclusivas.

Palavras chave: Roteirização turística; mapeamento participativo, roteiros turísticos.

Abstract: this essay aims to think about the analytical profitability of the concept of "participatory mapping" in the evaluation of social participation in the Brazilian tourist routing process. The need for this work arises in the contemporary context of ensuring greater role for the receiving population in the development of tourist activity in their living spaces. For this, a bibliographic review is made about the discussions of tourist routing in Brazil and about the recent cases of tourist routes in the country thought through participatory mapping The item highlighted in these analyzes is the degree of inclusion of the community. Thus, it will be possible to verify whether the current concept collaborates or not, significantly, to think and make tourist itineraries more inclusive.

Keywords: Tourist routing; participatory mapping, tourist routes. 


\section{Introdução - Roteirização turística no Brasil e as plataformas de discurso: questões iniciais.}

Há um consenso sobre o "gap" no Brasil acerca do tema roteirização turística. É um tema pertencente ao campo de discussões do turismo ainda incipiente. Esta situação faz parte do contexto de jovialidade do turismo como disciplina, em âmbito mundial. No entanto, isto não ocorre somente pela falta de amadurecimento dos estudos turísticos.

Dentro das discussões do turismo a roteirização não têm tido espaço adequado quando se leva em consideração a sua importância para o desenvolvimento da atividade. Conforme revela Adriana Tavares (2002) a causa da negligência sobre o assunto é a naturalização do roteiro unicamente como sequência de atrativos a serem visitados. Algo que não é passível de uma discussão racional. Seria apenas questão de preferência ou gosto. São os roteiros os principais responsáveis por delimitar os espaços que serão visitados e o direcionamento do fluxo de visitantes. Pensar em como são feitos, por quem e os principais beneficiários deste processo são questões essenciais na busca de um turismo responsável.

Entende-se por turismo responsável a atividade que seja capaz de gerar, antes de qualquer coisa, bem estar para as comunidades receptoras através do atendimento de seus interesses nas decisões que envolvam seus espaços de vida (LAZARINI e BARRETTO, 2014). A responsabilidade da atividade turística com a comunidade receptora também é tema em voga nos estudos turísticos. Conforme aponta Mirian Rejowski (2015) historicamente as teorias que pautam a atividade turística mostram maior ênfase no cuidado com os visitantes. É recente a preocupação com os visitados e seus espaços de vida.

A fim de contribuir para o aprofundamento das discussões relacionadas a roteirização turística no Brasil, atrelada ao desenvolvimento de um turismo responsável, este artigo dará ênfase no grau de participação e gerenciamento da comunidade local sobre a construção e implementação dos roteiros turísticos. Elas estarão diluídas ao longo do artigo na análise das plataformas.

As plataformas aqui tratadas são linhas de pensamento sobre a definição, finalidade e formas de aplicação da roteirização turística no Brasil. Foram assim organizadas, em tipos ideais, com a finalidade de perceber quais são os discursos existentes sobre o tema, suas nuances e os atores sociais em cena.

No decorrer da pesquisa bibliográfica foram identificadas duas plataformas discursivas: a governamental e a da iniciativa privada. O mapeamento participativo é um elemento teórico que surge como uma possível plataforma sobre o assunto diante a necessidade apontada por maneiras mais inclusivas de roteirizar no turismo. Neste sentido, este trabalho busca analisar a seguinte questão: o conceito de mapeamento participativo contribui significativamente nas discussões sobre a participação da comunidade nos processos de roteirização turística?

Ao buscar a resposta para este questionamento as plataformas discursivas serão apresentadas junto as suas diretrizes teóricas e 
práticas, devidamente contextualizadas, evidenciando principalmente as formas de inclusão da comunidade local nestes processos.

\subsection{A iniciativa privada e os roteiros turísticos}

A roteirização turística no Brasil foi iniciada pelo setor privado. A prática empresarial antecede a visão científica e as políticas governamentais no turismo (MOESCH, 2002). A roteirização, assim como outros processos advindos da atividade, teve início pelos agentes empresariais. É feita sob lógica do que traz mais lucratividade aos seus negócios com pouca preocupação dos seus impactos.

Os principais responsáveis pela produção da roteirização turística de iniciativa privada no Brasil são as agências de turismo. De acordo com José Dantas (2002) estas empresas podem ser definidas pela sua função principal: a de intermediação. De um lado, existe o interesse dos clientes por produtos relacionados a um deslocamento temporário, fora do entorno habitual, inferior a um ano, voltado principalmente para fins de lazer; entendido como turismo. Do outro, a oferta disponível de serviços que possibilitam todo o processo de ida ao destino, permanência temporária e retorno. São as agências que fazem o encontro destes lados.

O roteiro é entendido por estas empresas como um processo de planejamento contínuo para a comercialização e execução dos serviços turísticos para o consumidor. E ainda, pode ser também objeto de divulgação da empresa e seus produtos (SEBRAE, 2014).
Para sua confecção as agências de turismo contratam e negociam a prestação dos serviços de hospedagem, alimentação, transportes, guias de turismo, entre outros serviços. A presença ou não dos itens mencionados dependerá da modalidade de produto escolhida pelo cliente (SEBRAE, 2014).

\section{Figura 1: modelo de roteiro das Agências de Turismo Roteiro/programa Cidade Ideal}

\author{
Saida: (data) \\ $1^{\circ}$ dia \\ $9 \mathrm{~h}$ - Horário de chegada ao ponto de encontro (estação do \\ metrô). \\ $10 \mathrm{~h}$ - Encontro com os passageiros e início do embarque. \\ $11 \mathrm{~h}$ - Partida com destino a XYZ pela rodovia ZZZZZ. \\ $13 \mathrm{~h} 30$ (aproximadamente) - Parada técnica de quarenta mi- \\ nutos para almoço no $\mathrm{km} 0000$, no posto/restaurante. \\ $17 \mathrm{~h}$ - Chegada e acomodação no hotel Royal Royal XYZ. \\ Noite livre. \\ $2^{\circ}$ dia \\ $9 \mathrm{~h}$ - Saída para city tour com guia local. \\ $13 \mathrm{~h}$ - Retorno ao hotel. \\ Tarde livre. \\ Fonte: CHIMENTI e TAVARES (2013, p.104)
}

O modelo de roteiro apresentado na figura acima foi produzido didaticamente para o aprendizado de guias de turismo por Silvia Chimenti e Adriana Tavares (2013). O item segue o formato utilizado por agências de turismo. Nele é possível observar as 
2 Conhecidas no mercado turístico pelo nome de Agência de Turismo Receptivo (TAVARES, 2002) informações dos serviços a serem prestados durante uma viagem, assim como as datas e horários. Costuma ser entregue ao cliente no ato da contratação dos serviços. As agências de turismo produzem documento semelhante, com mais detalhamentos, para uso do responsável pela operacionalização da viagem; normalmente o guia de turismo.

O custo de operacionalização do roteiro, de manutenção da empresa e a busca do lucro diante dos serviços de intermediação prestados são a finalidade maior destas empresas. Conforme explica Miguel Bahl (2004) os custos de operacionalização do roteiro são referentes as despesas relacionadas a execução da viagem como: contratação do transporte, ingressos, guias de turismo, hospedagem, entre outros. Os de manutenção da empresa, de acordo com Petrocchi e Bona (2003), são os compromissos de pagamento de taxas (como água, luz, telefone, aluguel) e salários destinados ao funcionamento da empresa. O lucro é a quantia que sobressai mediante o pagamento das despesas operacionais e de manutenção da empresa. O valor costuma ser dividido entre proprietários e acionistas (PETROCCHI e BONA; 2003)

A lógica empresarial na criação dos roteiros privilegia somente o olhar do visitante em sua montagem. O roteiro turístico é entendido somente na sua dimensão de produto. Sendo assim, a lógica é a criação de uma mercadoria que busca atender o maior número possível de vontades do consumidor como forma de garantir sua satisfação. Assim, fideliza-se o cliente e consequentemente, mantém a longo prazo a lucratividade do negócio.
Tanto no processo de elaboração quando de operacionalização dos roteiros há pouca ou nenhuma preocupação com a comunidade receptora conforme sinalizam Adriana Tavares (2002) e Bianca Freire-Medeiros (2009). Tavares (2002) aponta que as agências de turismo, em geral, não se preocupam com os impactos causados pelos roteiros e nem com a geração de renda para a comunidade receptora. Há uma busca exclusiva em atender as expectativas dos clientes. Salvo, em raras exceções, quando os roteiros são elaborados por agências de turismo instaladas na região do destino turístico ${ }^{2}$ e os passeios são promovidos no seu entorno habitual (TAVARES, 2002).

Bianca Freire-Medeiros (2007) e (2009) reafirma as proposições de Adriana Tavares (2002) sobre as agências de turismo de forma mais detalhada. O contexto da fala da autora em voga é a pesquisa de campo sobre o turismo nas favelas da cidade do Rio de Janeiro. Ela afirma, resumidamente, que as agências de turismo promovem itinerários dentro das comunidades com uma visão unicamente comercial, sem compromisso com os residentes. Os promotores e operacionalizadores dos roteiros são, na maioria dos casos, pessoas externas à comunidade. No geral "[...]os turistas gastam muito pouco durante as visitas e, como não há nenhum tipo de distribuição dos lucros, os capitais suscitados pelo turismo são reinvestidos apenas minoritariamente na favela e sempre pela via da caridade" (FREIRE-MEDEIROS, 2007, p.66). Além disso, o roteiro reforça estereótipos negativos dos moradores das comunidades e sobre a localidade. 


\subsection{A plataforma governamental}

Diferente da iniciativa privada, o discurso do governo sobre roteirização turística está relacionado a uma ação política. Uma breve contextualização sobre o termo políticas públicas torna-se importante na plataforma governamental por ser um tipo de declaração que surge sob este formato. De acordo com Celina Souza (2003) não existe uma definição única ou melhor de política pública. Resumidamente o termo pode ser entendido como o processo pelo qual os governos "[...]traduzem seus propósitos em programas e ações, que produzirão resultados ou as mudanças desejadas no mundo real." (SOUZA, 2003, p.5). Ainda, de acordo com a autora mencionada, caberá ao pesquisador compreender porque os governos agem em tal direção. Isto implica em responder as seguintes perguntas: "o quê, por que e a diferença que faz" (SOUZA, 2003, p. 5). O termo "o quê" se refere as definições e objetivos da política pública. O "por que" é a justificativa para criação de tal política e a “diferença que faz" está relacionada ao impacto que causará na sociedade. Deve se levar em conta também os interesses por trás de tais políticas e os grupos favorecidos por elas, seja na execução ou no resultado final. Seguindo as sugestões investigativas deixadas por Souza (2003) é possível identificar com maior clareza o discurso da plataforma governamental e as questões da inclusão comunitária na roteirização turística.

A atividade turística surge no Brasil no início do século XX por influência do que já acontecia nos países europeus (SOLHA,
2005). O Turismo era um tipo de comportamento moderno, típico de países republicanos. A recém república brasileira buscava este novo ar de modernidade e o apagamento das memórias imperiais. O turismo surgiu como uma europeização dos hábitos e costumes em busca da modernidade. Foi pensado também pela jovem burguesia brasileira como uma oportunidade de negócio. Até meados da década de 1960 não havia uma preocupação por parte do governo com este tipo de atividade. Pode-se dizer então que não existia um discurso governamental consistente sobre o assunto. Somente algumas décadas depois surge, em âmbito federal, em 1966, a Empresa Brasileira de Turismo (EMBRATUR). Ela tinha como finalidade desenvolver políticas públicas para organização e desenvolvimento da atividade em todo território (AGUIAR, 2010). A Embratur é considerada a primeira política pública brasileira significativa em âmbito nacional (TRETIN e FRATUCCI, 2011). No entanto, a roteirização turística só ganha destaque no discurso governamental em 2005, 39 anos depois das primeiras políticas públicas de turismo e quase um século após o início das atividades turísticas no Brasil.

O discurso de roteirização turística aparece como política pública no final do primeiro mandato do presidente da república pertencente ao Partido dos Trabalhadores (PT) Luiz Inácio Lula da Silva, conhecido popularmente como "Lula". A roteirização turística ganhou força e espaço durante o segundo mantado da figura pública supracitada. Para Luis Barbosa (2012) ele representava no imaginário social uma oposição radical de ideais do governante 
${ }^{3}$ A sigla corresponde a abreviação do nome do ex-presidente da república Fernando Henrique Cardoso que esteve no cargo de 1994 até 2002.

no cargo de 1994 até 2002.
4 PNMT - Programa Nacional de Municipalização do Turismo. Vigorou no Brasil durante os dois mandatos presidenciais de FHC.

${ }^{5} \mathrm{O}$ texto de apresentação do Módulo Operacional 7 é da autoria de Marta Suplicy, na época, ministra do Turismo.

anterior. Tratava-se de [...] "uma transição paradigmática do antecessor paradigma neoliberal em crise, para um novo empreendido por sua administração, um "paradigma republicano" (BARBOSA ,2012 p.49). Entende-se por Republicano [...]a “intervenção do estado na esfera pública com preocupações muito maiores no tocante a área social (combate a exclusão, distribuição de renda, políticas de emprego e de crédito levadas em frente pelo governo federal)" (BARBOSA, 2012, p.49). Lula proporcionou diversos programas de transferência de renda que possibilitou o aumento de consumo das classes de baixa renda. No entanto, manteve as políticas econômicas próximas ao neoliberalismo, seguindo a linha do governo $\mathrm{FHC}^{3}$ e abandonando bandeiras mais radicais que propunha seu partido na década anterior (MACHADO, 2009).

No governo Lula houve uma reestruturação da gestão do turismo no território nacional. O Ministério do Turismo passa a ter as atribuições da antiga Embratur na regularização, fiscalização e promoção do turismo nacional. Há uma ruptura com as estratégias propostas pelo $\mathrm{PNMT}^{4}$ em prol de um modelo regionalizado (TRETIN, FRATUCCI, 2011). A roteirização turística torna-se peça fundamental dentro do Programa de Regionalização do Turismo Roteiros do Brasil e do Plano Nacional de Turismo - Uma viagem de inclusão (2007 - 2010) - no qual propõe inter-relacionamento para o desenvolvimento do turismo entre as várias esferas de poder. Busca a “superação da pobreza e da exclusão social provocadas pelo aprofundamento das desigualdades regionais" (BRASIL, 2007 b, p.12).

Os discursos sobre roteirização turística encontram-se detalhadamente em uma das obras da série publicada pelo governo no intuito de instruir tecnicamente os envolvidos no processo. $\mathrm{O}$ documento referente a roteirização turística é o "Módulo Operacional 7". Foi escrito em 2005, com reedição aperfeiçoada em 2007 para integrar a coleção supracitada. A obra define as diretrizes governamentais brasileiras para a elaboração e construção de roteiros turísticos com foco no desenvolvimento regional. Até o presente momento, esta é a única publicação do governo federal em voga que fala especificamente sobre roteirização turística.

O documento inicia explicando a ideia principal que fundamenta os planejamentos e formas de gestão de turismo no Brasil: a de descentralização. Segundo o texto do prefácio escrito por Marta Suplicy, o Brasil possui uma "gestão descentralizada do

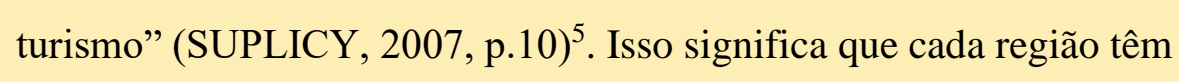
autonomia para decidir sobre como desenvolver o turismo em seu território de acordo com cada especificidade local.

O plano não busca somente separar ou agrupar municípios que possuam similaridades na oferta de produtos. Pretende ir além disso. Este tem a intenção de "construir um ambiente democrático, harmônico e participativo entre poder público, iniciativa privada, terceiro setor e comunidade". (SUPLICY, 2007, p.10). Mediante este ambiente relatado, pretende-se alcançar, em sentido amplo, os princípios da sustentabilidade econômica, ambiental, sociocultural e 
${ }^{6}$ A definição destes termos é a usada pelo Ministério do Turismo. Elas podem ser encontradas no documento intitulado "Inventário da oferta turística" publicado em 2011. Disponível em: http://inventario turismo gov br/invtur/d http://inventario.turismo.gov.br/invtur/d ownloads/formularios/inventariacao_da oferta_turistica.pdf $>$. Acesso em 09/05/2020.

${ }^{7} \mathrm{O}$ documento em análise define Marketing como "conjunto de técnicas utilizadas para a comercialização e a distribuição de um determinado produto entre os diferentes consumidores (BRASIL, 2007a, p.18).

8 Subentendido no texto em análise como agentes da iniciativa privada que possuem empresas diretamente e indiretamente ligadas a atividade turística. Na maioria das vezes as empresas ligadas à roteirização são as operadoras de turismo e agências de viagem político-institucional. Além disso, ao mesmo tempo em que promove a autonomia, coloca como consequência desta, a responsabilização de cada região pelo seu próprio desenvolvimento. Para tal empreitada é destacado a necessidade do protagonismo das comunidades receptoras.

A roteirização é uma estratégia, usada dentro da ideia de descentralização, para alcançar os objetivos gerais do turismo nacional acima mencionados. A construção do conceito de roteirização turística no documento é fundamentada a partir da ideia de roteiro turístico:

[...] um itinerário caracterizado por um ou mais elementos que lhe conferem identidade, definido e estruturado para fins de planejamento, gestão, promoção e comercialização turística das localidades que formam o roteiro. Partindo da definição anterior, pode-se dizer que a roteirização turística é o processo que visa propor, aos diversos atores envolvidos com o turismo, orientações para a constituição dos roteiros turísticos. Essas orientações vão auxiliar na integração e organização de atrativos, equipamentos, serviços turísticos e infra-estrutura de apoio do turismo, resultando na consolidação dos produtos de uma determinada região (BRASIL, 2007a, p.13)

A roteirização não é apenas uma determinação de um itinerário. Trata-se de uma política pública com o objetivo de proporcionar, nos próprios termos do texto, "desenvolvimento socioeconômico" (BRASIL, 2007a, p.13).
O resultado a ser alcançado é aumentar o fluxo de turistas, seu tempo médio de estadia no destino e seus gastos. Ou seja, visa o aumento do consumo de bens e serviços atrelados ao entretenimento e lazer por pessoas externas à localidade. Como consequências do aumento do fluxo turístico, são destacados no texto, melhor distribuição de renda advindas do aumento dos postos de trabalho e maior volume de recursos financeiros disponíveis na região. Há expectativa que estes recursos promovam a inclusão social e auxiliem na redução das desigualdades sociais. Serão estes recursos que possibilitarão o alcance dos objetivos propostos pela roteirização e pelo programa de regionalização.

Para a obtenção dos resultados traçados busca-se com a roteirização “organizar" e "integrar” a oferta turística brasileira (BRASIL, 2007a, p.13). Os elementos que a compõem e que serão alvo da integralização em um ou mais destinos são: os atrativos turísticos, serviços e equipamentos turísticos e serviços complementares ao turismo ${ }^{6}$.

O “organizar" é explicado como uma forma de dar um ordenamento lógico aos atrativos, que antes do roteiro, é pressuposto pelo Ministério do Turismo, não existir. Cabe questionar: esta lógica de organização é dada por quem e para quem? A lógica é dada pelo produtor do serviço ou bem por meio do Marketing ${ }^{7}$. Este ordenamento proposto deve não só esclarecer mas também atender as necessidades e expectativas do consumidor.

Os produtores nesta cadeia são o público intitulado como empresariado $^{8}$. Estes, junto a esfera pública municipal, são os

Dossiê Turismo: entrecruzamentos de cultura, memória e desenvolvimento 
responsáveis por organizar e motivar a participação no processo de roteirização. Isto é apenas um dos significados da palavra integrar no texto. O segundo significado existente é o de inserir os roteiros elaborados em um enquadramento de um grupo específico de produtos semelhantes, voltados para uma demanda segmentada. Todo este enquadramento é colocado estratégia de promoção e comercialização do produto turístico. Recomenda-se que isto deva ser feito pelo grupo do empresariado ou sob sua liderança.

Durante a análise do documento em voga percebeu-se uma discrepância de discurso. Inicialmente, logo em seu texto de abertura, há uma fala da ministra do turismo anunciando a roteirização como um processo sustentável e participativo, onde os protagonistas seriam a comunidade. No decorrer da leitura o tom da escrita muda: o processo parece buscar essencialmente o desenvolvimento econômico. Esta percepção é notada também por Melo (2014), Irving (2015) e Cisne (2016).

Quando o documento explica de uma forma generalizada de como se pretende desenvolver o turismo nacional por meio da roteirização é recorrente a ideia de participação comunitária e preocupações com o desenvolvimento social, ambiental, econômico e cultural. Na medida em que o discurso se aproxima de uma etapa tangível o tom do texto muda e torna-se predominantemente econômico. Em concomitância a isto há um desaparecimento das atribuições e benefícios para a comunidade.

Dossiê Turismo: entrecruzamentos de cultura, memória e desenvolvimento Arquivos do CMD, Volume 8, N.1. Jan/Jul 2020

\subsection{A necessidade de um olhar menos mercadológico e mais inclusivo sobre a roteirização turística brasileira.}

Percebe-se nas plataformas anteriormente apresentadas um pensamento comum sobre o papel da roteirização na atividade turística. Há um consenso sobre o assunto, em diferentes graus de percepção, sob a finalidade mercadológica deste processo. Este consiste em enxergar a roteirização turística predominantemente como mercadoria. Assim têm sido o procedimento adotado pelas empresas de turismo quando promovem roteiros sem inclusão local e com um itinerário de serviços organizados pela lógica única de atender os desejos do turista (CISNE, 2016). No mesmo caminho, o discurso da plataforma governamental entende a roteirização como forma de desenvolvimento econômico por meio da comercialização dos espaços de vida comunitários, no formato de produto turístico. Isso não seria problemático se fosse feito por pessoas residentes nestes lugares, em comum acordo (IRVING, 2015).

Entender a roteirização somente pelo viés do mercado, na visão de Rebecca Cisne (2016), é obstáculo epistemológico para a questão. Em outras palavras, torna o problema raso em seu aspecto reflexivo. A autora acredita que olhar os roteiros apenas sob o viés econômico impede uma discussão profunda. É necessário um pensar complexo sobre a roteirização. A complexidade está em enxergar de forma ampla outros fatores decorrentes da prática, indo além das causas econômicas.

Em concordância com esta linha de pensamento Marta Irving (2015) complementa ao afirmar que há também no Brasil uma 
tendência do setor governamental de interpretar o turismo prioritariamente sob a ótica econômica, distanciando-o dos seus compromissos sociais e ambientais. Isto pode ser observado nas políticas públicas e nos discursos que as justificam. Este tipo de enfoque, junto a exclusão da comunidade local, pode causar por meio do turismo aumento das mazelas sociais.

Na mesma direção, Silvana Pirillo Ramos (2012) realça a necessidade de estudos sobre roteirização que possuam caráter interdisciplinar. A interdisciplinaridade facilitaria diversos modos de ver e pensar o processo de roteirização com superação a visão econômica dominante. Isto permitiria vencer o estereótipo do turismo como panaceia para as destinações e pensá-lo como uma atividade que requer manejo de todos os setores da sociedade para alcançar uma prática responsável.

Para isso, Ramos (2012) recomenda rever o ato do planejamento de roteiros para uma abordagem que interaja com a comunidade local e leve em conta as diferentes representações dos lugares visitados. Não basta apresentar diversos atrativos turísticos em série, como tem sido feito pelas agências de turismo. É necessário evidenciar o "porque conhecer" e "como conhecer" (RAMOS, 2012, p.8).

A autora em questão enfatiza em todo seu texto a urgência de inclusão da comunidade neste processo. O turista, quando não se conecta de alguma forma com os moradores locais, não consegue conhecer significativamente o destino. Apenas percorreu um espaço geográfico não habitual presente nos mapas, o que contradiz o propósito do fazer turismo. A atividade deve buscar em sua essência, vivenciar, na medida do possível, a cultura do outro. Isto pode, e deve ser, o objetivo maior da roteirização. Para isso, o roteiro precisa permitir que o visitante construa significados sobre o lugar pela ótica cotidiana do visitado.

Nesta diretriz, Marta Irving (2015) salienta que a inclusão da comunidade nas atividades turísticas e no processo de roteirização não pode ser passiva. As populações locais devem ser os principais protagonistas no processo sendo, simultaneamente, atores e autores dos roteiros a serem construídos. Entretanto, há uma desconexão entre este discurso e a prática da roteirização turística.

Conforme afirma Ramos e Santos (2012) na ausência de um encaminhamento prático de ações que atendam os pressupostos inclusivos e sustentáveis, o setor turístico, mesmo os mais militantes quanto as causas sociais, produzem a roteirização por meio da tentativa “ensaio e erro" (RAMOS e SANTOS, 2012, p.34). Este método consiste em fazer ações, sem muita reflexão e planejamento, para alcançar os objetivos propostos. As medidas também contam com a subjetividade dos gestores sobre o que deve ser feito.

Para completar o quadro, o que é executado, na maioria das vezes, não possui um lastro fundamentado por estudos científicos que garantam sua eficácia. Isto é um risco para a comunidade, na medida que, a sustentabilidade e o turismo responsável, tornam-se apenas discursos de boas intenções, de progresso, desenvolvimento, melhoria da humanidade e, podem acabar, na prática, vir a ser o reverso. 


\subsection{O mapeamento participativo como possibilidade de plataforma para roteirização turística}

Mediante leitura da obra organizada por Henri Acselrad (2008) constata-se que a ideia de mapeamento participativo é fundada nas reflexões sobre o mapear e seus propósitos. Esta discussão inicia-se a partir da desnaturalização do conceito de mapa. Nela, ele deixa de ser um elemento neutro que retrata de maneira apolítica o espaço. Transforma-o de verdade absoluta e apartidária em um ato político passível de questionamento.

Por "ato político" entende-se que os mapas possuem intenções e ideologias na representação das informações na medida que constrói, enfatiza, minimiza e apaga elementos territoriais para seu leitor. $\mathrm{O}$ conteúdo é resultado da forma de ver do confeccionador. Este olhar carrega em si as acepções históricas e sociais do qual o indivíduo faz parte. Assim, o mapa é um documento que revela, dentre outras informações, as representações sociais e culturais de uma sociedade (CRAMPTON e KRYGIER, 2008). Nas palavras de Henri Acselrad e Luis Coli (2008, p.13) os mapas não são “um reflexo passivo do mundo dos objetos, mas um intérprete de uma determinada verdade, em que o crer se localiza no ver".

Neste sentido, o mapa, por vezes, equivale a um longo discurso que favorece determinados grupos sociais e visões de mundo (ACSCELRAD, 2008). Para que estes elementos discursivos fiquem mais claros e passíveis de análise, os mapas devem desvencilhar-se do seu caráter objetivo de produção e assumir plenamente sua subjetividade (JOLIVEAU, 2008).

Diante das questões levantadas surgiu um movimento na área de estudos da cartografia no qual entende que os mapas não devem mais ser fornecidos apenas por especialistas (JOLIVEAU, 2008). O mapa é um instrumento de poder capaz de produzir espaços e identidades políticas. Portanto, precisa ser construído pela comunidade territorialmente retratada. Assim, o mapeamento será um poderoso meio de promover a transformação social (PICKLES 2004). Além disso, os mapas tonam-se um caminho para uma forma interpretação democrática e um instrumento de resistência contra mecanismos autoritários de controle. É neste contexto que surge a prática do mapeamento participativo (ACSELRAD e COLI, 2008).

De acordo com Peter H. Herlihy e Gregory Knapp (2003) o mapeamento participativo é uma nova maneira de produzir informações geográficas, sobre pessoas e lugares, por meio do reconhecimento das informações sociais, ambientais e espaciais fornecidas pela própria comunidade. Este tipo de mapeamento envolve diretamente os moradores locais no levantamento dos dados do território, assim como das suas fronteiras e limites. O processo busca preservar a maneira de organização simbólica e mental do lugar produzida pelo grupo residente.

O método tem suas raízes nas premissas na observação participante e pesquisa colaborativa. Com o auxílio de pesquisadores as categorias nativas sobre o espaço são retratadas de modo a ser 
${ }^{9}$ Para maiores informações sobre este estudo de caso ver a dissertação de Rocha (2019). Informações completas sobre a obra podem ser encontradas na referências bibliográfica. universalizadas paras uso de qualquer pessoa e grupo, interno ou externo a comunidade. Os dados coletados são interpretados pelos moradores. O pesquisador é apenas um canal que contribui para a formalização dos conhecimentos retratados. (HERLIHY e KNAPP 2003).

Cabe enfatizar que o processo de mapeamento só é considerado participativo quando construído em cocriação com os moradores locais. Esta visão permite a representatividade e empoderamento da comunidade residente perante os outros agentes sociais na disputa pelos recursos presentes no território. Além disso, fortalece o tecido social, na medida que, reconhece a capacidade organização da população em questão para traçar as diretrizes de entendimento do seu território. E ainda, pode ser uma ferramenta que permite compreender a relação homem - ambiente.

A roteirização turística, por meio de mapeamento participativo, tem também em seu âmago a problematização no mapa. No caso específico do turismo, entende-se aqui preliminarmente por mapa o desenho gráfico (impresso ou digital) que informa e orienta o deslocamento do turista para os atrativos, serviços e equipamentos turísticos e complementares. O mapa, sob a ótica do turismo, pode ser entendido como um roteiro. Esta equivalência nos permite deduzir que, assim como os mapas, os roteiros não apresentam uma verdade absoluta e neutra sobre os lugares visitados. Estes são um ato político, conforme proposto por Acselrad (2008), que representam o interesse e o olhar de seus produtores sobre o território.
Diferente dos mapas cartográficos, não existe uma padronização existente para a confecção material de roteiros. Este ponto apresenta um elemento positivo e negativo com relação a inclusão da comunidade. O ponto positivo é que por ausência de uma tradição técnica de produção, os roteiros são construídos de acordo com a vontade dos seus produtores e patrocinadores. O ponto negativo é diretamente relacionado ao positivo. A determinação do que será ou não retratado, assim como sua dimensão, dependerá diretamente dos interesses de quem produz ou patrocina o roteiro. $\mathrm{O}$ mapeamento participativo dilui o ponto negativo abordado e potencializa o positivo, na medida que, proporciona na comunidade uma discussão ampla do que deve ou não ser representado.

Um exemplo prático desta questão é abordado por Rocha (2019) na proposta de um roteiro turístico cultural em Penedo - RJ. Por meio do método de mapeamento participativo, foi confeccionado um o roteiro sobre a cultura finlandesa. A proposta surgiu após constatar, em pesquisa de campo junto à comunidade, o domínio dos shoppings centers no cenário turístico do destino. A maior parte do movimento turístico local concentra-se em torno destes empreendimentos empresariais de caráter não comunitário. Isto se deve, principalmente, pela ausência no destino turístico de mecanismos que oportunizem o turista a conhecer outras narrativas de finlanidade no lugar ${ }^{9}$. Assim, o imaginário turístico, fator impulsionador da visita dos destinos (URRY, 2001), ficou concentrado na imagem dos shoppings. 
${ }^{10}$ Sigla para Mapeamento Participativo. 11 O texto original está em língua inglesa. $\mathrm{O}$ trecho utilizado está em português por meio de tradução livre.
O roteiro desenvolvido por mapeamento participativo buscou dar luz a outros comércios e atrativos turísticos locais relacionados a cultura finlandesa. Todos os lugares auto identificados com a proposta foram incluídos no roteiro final, até mesmo os shoppings. A ideia não tinha o intuito de julgar o que devia ou não ser visitado e sim colocar todas as narrativas existentes em equidade por meio de um roteiro. O autor acredita que inclusão também se dará, ao longo do tempo, pela redistribuição dos visitantes no destino.

A intenção de trazer este exemplo à tona não é falar sobre o caso específico de Penedo - RJ, e sim, ilustrar que o espaço turístico é um lugar de disputas. A construção de um roteiro torna-se política na medida que, gera associações e conflitos entre os atores sociais durante o processo de intervenção nos elementos culturais.

A aplicação dos princípios de Mapeamento Participativo ao turismo permite incorporar seus benefícios à prática da atividade. $\mathrm{A}$ confecção de roteiros por este meio pode transformar as rotas desenvolvimentistas, propostas pela plataforma governamental, e as programações turísticas simplistas, vendidas nas agências de turismo, em um mecanismo complexo de desenvolvimento territorial que incorpora a participação ativa comunitária.

Para além dos benefícios que são inerentes ao método, o mapeamento permite a problematização da formulação de roteiros. Agora, não se trata apenas de ordenar um itinerário de acordo com as vontades do turista, do capital ou da subjetividade do gestor. Trata-se de entender as questões existentes em uma localidade e conciliar os discursos dos grupo em cena, assim como seus interesses. Isto proporciona inclusão social e consequentemente o desenvolvimento de um turismo responsável na medida em que se compromete com a vontade dos grupos envolvidos na atividade.

\subsection{O Caminho em direção a roteirização turística por meio de MP10}

O mapeamento participativo transforma o conhecimento cognitivo em mapas, formas gráficas ou escritas[...]Algumas generalizações podem agora ser eitas sobre essa metodologia em rápido desenvolvimento, apesar das diferenças técnicas e filosóficas significativas entre projetos e profissionais O mais fundamental é o uso da população local para mapear o local. A metodologia baseia-se na filosofia de que as populações locais têm alguns dos melhores e mais detalhados conhecimentos de suas terras e recursos circundantes e que esse conhecimento pode ser coletado e interpretado geograficamente" [...] em mapas, formas gráficas ou escritas [...] Geralmente, isso significa realizar reuniões da comunidade, isso significa realizar reuniôes da comunidade administrar questionários, registrar nomes de lugares, desenhar esboços, criar diagramas, coletar dados de campo e plotar informações cognitivas sobre o local diretamente nas folhas cartográficas padrão ${ }^{11}$. (HERLIHY e KNAPP 2003, p. 307)

Conforme explicam Peter H. Herlihy e Gregory Knapp (2003) não há uma forma única para realização do mapeamento participativo. No entanto, existem algumas premissas básicas. Ou seja, alguns pressupostos e procedimentos indispensáveis que caracterizam o método, conforme descrito sucintamente na citação. Como estes passos, poderiam ser formulados para a orientação de 
12 É uma associação civil sem fins lucrativos que tem como um de seus objetivos oferecer apoio técnico a projetos turísticos comunitários. Estas informações sobre a instituição foram retiradas do seu estatuto de fundação. Disponível em:

http://brasilidadesolidariacom br/wpcontent/uploads/2018/04/ESTATUTORBS_Final.pdf> . Acesso em: RBS_Final um mapeamento participativo voltado para a roteirização turística? Ao enfatizarmos este questionamento é possível entender com mais clareza os aspectos tangíveis que são propostos por esta plataforma.

$$
\text { Ao fazer o aproximação teórica procedimental do }
$$

mapeamento participativo com o campo do turismo, junto a estudos de caso que usam tal metodologia, chegou-se a três etapas que são consideradas essenciais. O primeiro passo consiste o contato e aceitação da comunidade. O segundo, uma pesquisa sobre os aspectos socioambientais do lugar e seus habitantes. O terceiro, a realização de reuniões para discussões e apresentações dos resultados.

Para o primeiro passo é preciso ir ao encontro da comunidade do lugar onde se pretende roteirizar turisticamente e saber se há o interesse na realização do projeto. Caso o turismo já exista na localidade é interessante saber se há reivindicações dos moradores com relação aos impactos positivos e negativos da atividade. Devese discutir amplamente as responsabilidades, benefícios e malefícios que a construção da roteirização venha a causar. A figura abaixo ilustra a efetivação deste passo. O trabalho é realizado por Talita Linhares (2016) no município de Campos dos Goytacazes - RJ. Havendo sinalização de aceite por parte da comunidade, parte-se para a próxima etapa.
Figura 2: Reunião com os moradores em Campos do Goytacazes - RJ

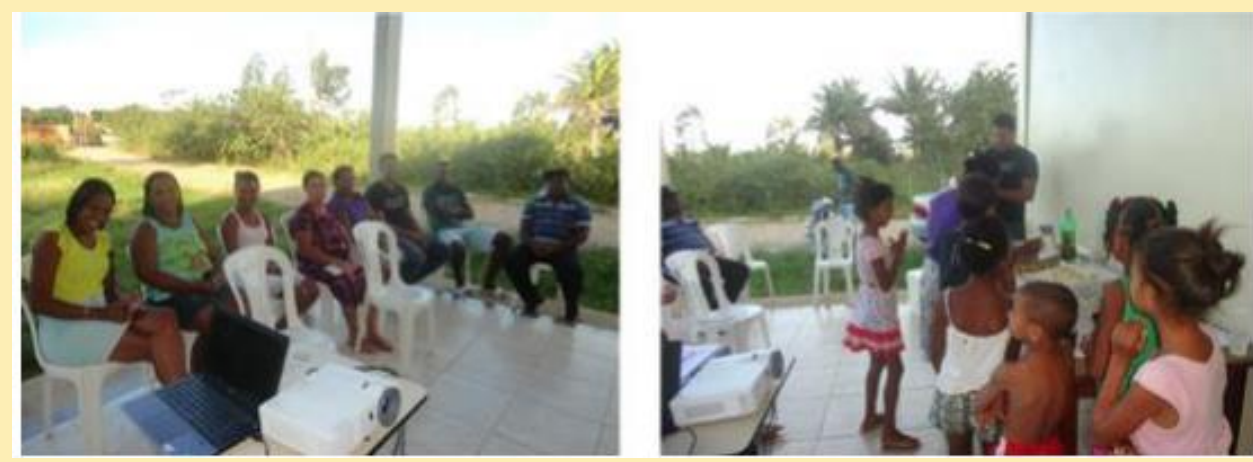

Fonte: LINHARES (2016, p.43)

No segundo passo é necessário um levantamento documental e pesquisa de campo, junto a observação participante na comunidade. É necessário conhecer o lugar de maneira holística a fim de entender a sua dinâmica cotidiana. Isso envolve analisar infraestrutura básica: saneamento, segurança, saúde, transportes entre outros. Envolve também questões específicas ligadas ao recebimento de visitantes como: possibilidades de hospedagem, alimentação e entretenimento. Nesta fase é interessante criar caminhos para ter a confiança da comunidade. Isto possibilita identificar, com mais facilidade, os interesses dos grupos residentes em torno da atividade turística, existente ou vindoura; o que pode facilitar a etapa seguinte.

Figura 3: A convivência com a comunidade e a observação participante na comunidade Quilombola em Campos dos Goytacazes - RJ 


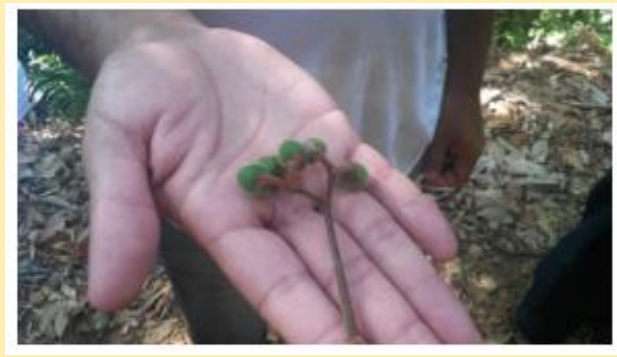

Fonte: LINHARES (2016, p.42)

O terceiro passo é reunir os diversos discursos da comunidade sobre os lugares que podem receber visitantes e a forma como isso deve ocorrer. É comum na aplicação do mapeamento participativo o uso de oficinas lúdicas que promovem, por meio do desenho, a localização dos lugares e sua dinâmica com os outros. Esta técnica foi utilizada no caso relatado por Cleber Castro e Rafael Fortunato (2014) para criação de novos atrativos turísticos por meio da Rede Brasilidade Solidária ${ }^{12}$, no município de Teresópolis - RJ.

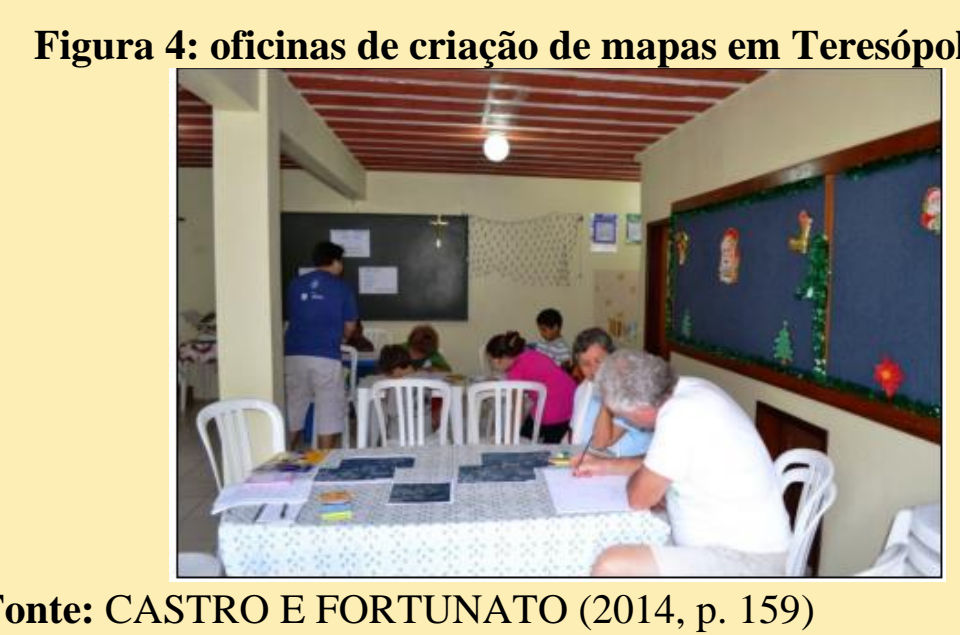

Dossiê Turismo: entrecruzamentos de cultura, memória e desenvolvimento Arquivos do CMD, Volume 8, N.1. Jan/Jul 2020
Cabe ressaltar que estes passos identificados são etapas comuns encontradas em componentes teóricos e trabalhos práticos sobre o mapeamento participativo turístico. Não existe um caminho único nesta metodologia. A medida em que há um aprofundamento local da roteirização turística as etapas ganham maior singularidade de acordo com os cenários observados.

\section{Considerações finais}

O presente ensaio buscou investigar a capacidade do conceito de mapeamento participativo, quando aplicado a roteirização turística, de gerar uma plataforma discursiva capaz de trazer avanços nos processos de inclusão da comunidade local nos estudos sobre formulação de roteiros turísticos no território brasileiro. Para isso, foram apresentados os discursos existentes sobre o pensar e fazer da roteirização turística. No levantamento bibliográfico foram encontrados duas visões sobre o tema. Elas foram agrupadas em plataformas: a das empresas de turismo (iniciativa privada) e a governamental (poder público federal).

Ao analisar tais plataformas percebeu-se a ênfase mercadológica presente em ambas. A da iniciativa privada em formular roteiros exclusivamente para agradar seus turistas com o objetivo único do lucro. A plataforma governamental de transformar os lugares em produtos turísticos na expectativa de vendê-los aos visitantes e com isso gerar o crescimento da economia.

A questão da inclusão não aparece nos discursos das empresas de turismo na formulação de roteiros. No discurso do 
poder público a inclusão é um fator que surge agregado ao desenvolvimento econômico. O governo entende que o turismo é predominantemente uma atividade geradora de renda. Prega-se que através dos efeitos gerados na economia as comunidades serão incluídas, pois terão recursos para consumir. Entretanto, nos processos decisivos da roteirização a participação da comunidade é secundária. E o que costuma ocorrer é a exclusão dos moradores no controle da atividade turística em seus espaços de vida. Gera também uma certa contradição entre o que se promete e as ações propostas para alcançar tais anseios.

Conforme alertam alguns dos pesquisadores mencionados neste ensaio o turismo têm sido analisado enfaticamente por uma ótica mercadológica. É necessária uma visão interdisciplinar que dê visibilidade a outras facetas que envolvem a atividade. A inclusão é um fator que têm sido negligenciado na roteirização turística e em outras abordagens dentro da disciplina. O que pode ser problemático para o seu desenvolvimento sob o viés responsável. Assim, apontase a necessidade de novos discursos e práticas que deem ênfase a participação comunitária.

O conceito de mapeamento participativo é colocado neste debate na tentativa de pensar modelos teóricos e práticos mais inclusivos no processo de roteirização turística. Na medida em que propõe novas formas de se pensar e fazer o roteirizar ele torna-se um novo discurso, ou seja, uma plataforma sobre a questão no cenário turístico. O intuito dela é trazer a participação ativa da comunidade na roteirização turística, e com isso, maior domínio sobre o crescimento do turismo em seu cotidiano.

Neste sentido, acredito que a plataforma do mapeamento participativo contribui para o debate em torno de uma roteirização turística inclusiva e consequentemente mais responsável. Nasce também uma alternativa de discurso na arena de disputas do conhecimento turístico. Para consolidação desta plataforma cabe a realização de mais estudos metodológicos sobre a aplicação deste tipo de roteirização em casos reais. Que esta reflexão aqui apresentada possa contribuir para o fortalecimento deste conceito na roteirização turística e para mais práticas verdadeiramente inclusivas.

\section{Referências}

ACSELRAD, Henri. Introdução. In: ACSELRAD, Henri (org.). Cartografias sociais e território. Rio de Janeiro: UFRJ/IPPUR, 2008.

ACSELRAD, Henri; COLI, Luis Régis. O lugar dos mapas nas abordagens participativas. In: ACSELRAD, Henri (org.). Cartografias sociais e território. Rio de Janeiro: UFRJ/IPPUR, 2008.

AGUIAR, Leila Bianchi. Estado, turismo, cultura e desenvolvimento: organização empresarial e a construção do consenso sobre a importância do turismo para o Brasil. Anais. In: VI Simpósio Nacional Estado e Poder: Cultura, Rio de Janeiro, 2010. Disponível em: 
https://www.historia.uff.br/estadoepoder/6snepc/GT1/GT1-

LEILA.pdf> Acesso em: 28/06/2020.

BAHL, Miguel. Viagens e roteiros turísticos. Curitiba: Protexto, 2004.

BARBOSA, Luis Guilherme Camfield. Governo Lula e a política econômica brasileira: continuidade ou ruptura? Revista Todavia, Ano 3, $n^{\circ} 4$, jul. 2012

BRASIL. Ministério do Turismo. Coordenação Geral de Regionalização. Programa de Regionalização do Turismo - Roteiros do Brasil: Módulo Operacional 7 Roteirização Turística/ Ministério do Turismo. Secretaria Nacional de Políticas de Turismo. Departamento de Estruturação, Articulação e Ordenamento Turístico. Coordenação Geral de Regionalização. - Brasília, 51 p. 2007a.

BRASIL. Ministério do Turismo. Coordenação Geral de Regionalização. Programa de Regionalização do Turismo Introdução a Regionalização do Turismo/Ministério do Turismo. Secretaria Nacional de Políticas de Turismo. Departamento de Estruturação, Articulação e Ordenamento Turístico. Coordenação Geral de Regionalização. - Brasília, 51 p. 2007 b.

CASTRO, Cleber Marques de; FORTUNATO, Rafael Ângelo. Redes populares de turismo e experiências de mapeamento participativo: a atuação da Rede Brasilidade Solidária em Teresópolis (RJ). Revista Continentes (UFRRJ), ano 3, n. 5, p.150$161,2014$.

CHIMENTI, Silvia; TAVARES, Adriana de Menezes. Guia de turismo: o profissional e a profissão. São Paulo: Senac, 2013.

CISNE. Rebecca. Roteiro turístico, do simples ao complexo: necessidade de reflexões. In: Fórum Internacional de Turismo do Iguaçu. Anais. Foz do Iguaçu - PR, jun, 2016. Disponível em: < http://festivaldascataratas.com/wp-content/uploads/2017/04/9.-

ROTEIRO-TUR\%C3\%8DSTICO-DO-SIMPLES-AO-
COMPLEXO-A-CESSIDADE-DE-REFLEX\%C3\%95ES.pdf>.

Acesso em: 25/04/2020

CRAMPTON, Jeremy; KRYGIER, John. Uma introdução à cartografia crítica. In: ACSELRAD, Henri (org.). Cartografias sociais e território. Rio de Janeiro: UFRJ/IPPUR, 2008.

DANTAS, José Carlos de Souza. Qualidade do atendimento nas Agências de Viagens. Uma questão de gestão estratégica. São Paulo:Rocca, 2002.

FREIRE - MEDEIROS, Bianca. A favela que se vê e que se vende. Reflexões e polêmicas em torno de um destino turístico. Revista Brasileira de Ciências Sociais - vol. 22 №. 65. 2007. Disponível em: $<$ https://www.scielo.br/pdf/rbcsoc/v22n65/a06v2265.pdf $>$. Acesso em: 07/05/2020.

FREIRE - MEDEIROS, Bianca. Gringo na Laje: produção, circulação e consumo da favela turística. Rio de Janeiro: Editora FGV, 2009.

HERLIHY, Peter; \& KNAPP, Gregory. Maps of, by and for the Peoples of Latin America. Human Organization. Journal of the Society for Applied Anthropology, v. 62, n. 4, inverno de 2003. Disponível em: 182

https://www.researchgate.net/publication/251914689_Maps_of_By_ and_For_the_Peopl es_of_Latin_America. Acesso em: 14 jan. 2019.

IRVING, Marta de Azevedo. Turismo, áreas protegidas e inclusão social: uma inclusão necessária em planejamento, no caso brasileiro. In: IRVING, Marta de Azevedo et al. (org.). Turismo, áreas protegidas e inclusão social. Diálogos entre saberes e fazeres. Rio de Janeiro: Folio digital, 2015.

JOLIVEAU, Thierry. O lugar dos mapas nas abordagens participativas. In: ACSELRAD, Henri (org.). Cartografias sociais e território. Rio de Janeiro: UFRJ/IPPUR, 2008. 
LAZARINI, Ricardo; BARRETTO, Margarita. Políticas públicas para no Brasil para um Turismo Responsável. Revista Turismo Visão e Ação - eletrônica, vol . 16 - n. 1 - Jan. - abr. 2014. Disponível

https://siaiap32.univali.br/seer/index.php/rtva/article/view/5945.

Acesso em: 07 jul. 2020.

LINHARES, Talita dos Santos. Diagnóstico do potencial turístico em comunidades tradicionais a partir da gestão participativa. 2016.

57 p. Dissertação (mestrado em Engenharia Ambiental) Instituto Federal de Ciência e Tecnologia Fluminense - IFF. Disponível em: < http://portal1.iff.edu.br/pesquisa-e-inovacao/pos-graduacao-stricto->.

Acesso em: 29/04/2020.

MACHADO, Eliel. Governo Lula, neoliberalismo e lutas sociais. Revista Lutas Sociais. n²3, Puc- São Paulo jul, 2009. Disponível em: $<$ https://revistas.pucsp.br/ls/issue/view/1198/showToc $>$. Acesso em: 25/06/2020.

MELO, Marisa Egrejas de. Roteirização diagonal: a construção de roteiros turísticos com a participação da comunidade local. 2014. 163 p. Tese (Doutorado em Engenharia de Produção) Universidade Federal do Rio de Janeiro - UFRJ. Disponível em:< http://www.pep.ufrj.br/index.php/en/theses-anddissertations/doutorado/2014-1. > Acesso em: 05/05/2020.

MOESCH, Marutschka. A produção do saber turístico. São Paulo: Contexto, 2002.

PETROCCHI, Mário; BONA, André. Agências de turismo. Planejamento e gestão. São Paulo: Futura, 2003.

PICKLES, John. 2004. A History of Spaces. Cartographic Reason, Mapping and the Geo-Coded World. London: Routledge. Disponível em: < https://epdf.pub/queue/a-history-of-spaces-cartographicreason-mapping-and-the-geo-coded-world-frontier.html>. Acesso em: 07/05/2020.

Dossiê Turismo: entrecruzamentos de cultura, memória e desenvolvimento
RAMOS, Silvana Pirillo. Apresentação. In: Ramos, Silvana Pirillo (org.). Planejamento de Roteiros turísticos. Porto Alegre, RS: Asterisco, 2012.

RAMOS, Silvana Pirillo; SANTOS, Angela Meire dos. Traçando itinerários para um turismo de experiência: o caso do caminho de lagunar - AL. In: Ramos, Silvana Pirillo (org.). Planejamento de Roteiros turísticos. Porto Alegre, RS: Asterisco, 2012.

REJOWSKI, Mirian. Teorizações do turismo em direção a novas abordagens: uma discussão preliminar. Anais. In: Seminário da Associação Nacional de Pesquisa e Pós-Graduação em Turismo (ANPTUR). São Paulo, 12. 2015.Anais [...]. São Paulo: ANPTUR, 2015. Disponível em: https://www.researchgate.net/publication 1309728259_Teorizacoes_do_turismo_em_direcao_a_novas_aborda gens_uma_disc ussao_preliminar. Acesso em: 07 jul. 2020.

ROCHA, Diego Uliano. Quer conhecer a Finlândia? Vá a Penedo! Uma proposta de roteiro turístico cultural. 2019. 190 p. Dissertação (mestrado em Bens Culturais e Projetos Sociais) Centro de Pesquisa e Documentação em História Contemporânea - CPDOC, Fundação Getúlio Vargas - FGV. Disponível em: < https://bibliotecadigital.fgv.br/dspace/bitstream/handle/10438/27460/ disserta\%c3\%a7\%c3\%a3o\%20vers\%c3\%a3o\%20definitiva.pdf?sequ ence $=1 \&$ is Allowed $=\mathrm{y}>$. Acesso em: 04/05/2020.

SEBRAE. Roteiros de turismo. Resposta técnica (2014). Disponível em: < http://www.sebraemercados.com.br/wpcontent/uploads/2015/11/2014_08_13 RT_Agosto_Turismo_Criaca oRoteiros_pdf.pdf >. Acesso em: 21/04/2020.

SOLHA, Karina Toledo. Evolução do Turismo no Brasil. In: REJOWSKI, Mirian (org.). Turismo no percurso do tempo. São Paulo: Aleph, 2002.

SOUZA, Celina. "Estado da Arte" da área de Políticas Públicas: Conceitos e principais tipologias. Anais. XXVII Encontro Anual da Associação Nacional de Pós-Graduação e Pesquisa em Ciências Sociais (ANPOCS); GT: Políticas Públicas. Caxambu, MG 21-25 de 


\section{Diego Uliano Rocha}
outubro
de
2003.
Disponível
em: $<$
https://anpocs.com/index.php/papers-27-encontro-2/gt-24/gt14-

16/4232-csouza-estado-da/file> Acesso em: 28/06/2020

SUPLICY, Marta. Apresentação. In: BRASIL. Ministério do Turismo. Coordenação Geral de Regionalização. Programa de Regionalização do Turismo - Roteiros do Brasil: Módulo Operacional 7 Roteirização Turístical Ministério do Turismo. Secretaria Nacional de Políticas de Turismo. Departamento de Estruturação, Articulação e Ordenamento Turístico. Coordenação Geral de Regionalização. - Brasília, 51 p. 2007.

TAVARES, Adriana de Menezes. City Tour. São Paulo: Aleph, 2002.

TRENTIN, Fábia; FRATUCCI, Aguinaldo C. Política nacional e turismo no Brasil da municipalização à regionalização. Book of proceedings. International Conference on Tourismo \& Management Stuies, Algarve 2011. Disponível em: https://edisciplinas.usp.br/pluginfile.php/1990063/mod_resource/con tent $/ 1 / \mathrm{Pol} \% \mathrm{C} 3 \%$

ADtica $\% 20$ Nacional\%20de\%20Turismo\%20no\%20Brasil\%20da\%2 Omunicipaliza\%C

3\%A7\%C3\%A3o\%20\%C3\%A0\%20regionaliza\%C3\%A7\%C3\%A3 o.pdf. Acesso em: 07 Jul. 2020.

URRY, John. $O$ olhar do Turista. Lazer e viagens nas sociedades contemporâneas. São Paulo: Studio Nobel: SESC, 2001

ZAI, Clotilde; SAHR, Cicilian Luiza Lowen. Roteirização turística como instrumento de desenvolvimento territorial: o roteiro 'verde que te quero verde' De Campo Magro/ Paraná (Brasil). Revista Finisterra, LIV(110), 2019, pp. 135-154. Disponível em: < http://www.scielo.mec.pt/scielo.php?script=sci_abstract\&pid=S0430 -502. Acesso em: 20/04/2020. 